\title{
REVISIÓN
}

\section{Propuesta para el control del agua de lastre en buques que arriban a puertos de la Ecorregión Marina de Chile Central}

\author{
Proposal for controlling ballast water in ships visiting ports of Central Chile Marine Ecoregion
}

\author{
Sandra Baro-Narbona ${ }^{1 *}$ y Wolfgang Stotz ${ }^{1}$ \\ ${ }^{1}$ Grupo de Ecología y Manejo de Recursos (ECOLMAR), Universidad Católica del Norte, Larrondo 1281, Coquimbo, Chile \\ *Corresponding author: sknarbona@gmail.com
}

\begin{abstract}
Shipping is essential to the economy. With the technological advance and faster vessels, the frequency of transoceanic trips has increased, increasing the risk of negative environmental and socio-economic impacts associated with the uncontrolled discharge of ballast water. Being this the water loaded by the ships to conserve its stability and maneuverability, but that takes matters in suspension, including biological agents, which can generate bioinvasions. Due to the above, and recognizing the importance of a precautionary approach, it is necessary to have a preventive management tool that allows to discern when unload ballast water is potentially dangerous. In this review, a tool based on the frequency and volume of ballast water coming from the same source port, the environmental similarity between the source and recipient port, and the presence of risky species in the source port, is proposed. A Coefficient of Global Risk (CRG) has to be estimated for each vessel arriving at the port in order to evaluate if the ballast water can be unloaded. For values of CRG $>16 \%$, which means it is likely the risk, it is necessary to verify if the required replacement of ballast water in the open sea has been done in compliance with international regulations. It is recommended in situ measurements of the Chromophoric Dissolved Organic Matter (CDOM) since it allows the discrimination between coastal and oceanic water. If the ballast water turns out to be of coastal origin the lack of compliance of the regulation can be detected, thus preventing the discharge of that water in the port area.
\end{abstract}

Key words: Verification, management, treatment, ballast water

Resumen.- La navegación marítima es esencial para la economía. Con el avance tecnológico y buques más rápidos, la frecuencia de los viajes transoceánicos ha aumentado, incrementando el riesgo de impactos negativos ambientales y socio-económicos asociados a la descarga descontrolada de agua de lastre. Esta agua es cargada por los buques para conservar su estabilidad y maniobrabilidad, pero que lleva materias en suspensión, incluyendo agentes biológicos, que pueden generar bioinvasiones. Por lo anterior, y reconociendo la importancia de un enfoque precautorio se hace necesario contar con una herramienta de gestión preventiva que permita discernir cuando el deslastre es potencialmente peligroso. Esta revisión propone una herramienta basada en la frecuencia y volumen del agua de lastre desde un mismo puerto de origen, la similitud ambiental entre el puerto de origen y el receptor del lastre y la presencia de especies de riesgo en el puerto de origen. Para esto se desarrolló el cálculo de un Coeficiente de Riesgo Global (CRG), que deberá ser estimado para cada buque que arribe al Puerto antes de que inicie el deslastre. Si CRG $>16 \%$, el riesgo es probable, entonces correspondería verificar el recambio de agua de lastre en aguas oceánicas como lo exigen las regulaciones internacionales. Se recomienda medir in situ la Materia Orgánica Cromofórica Disuelta (CDOM por sus siglas en inglés), ya que permite discriminar entre agua costera y oceánica. Si del análisis resulta que el agua es costera, significa el incumplimiento del intercambio del agua de lastre en alta mar, entonces se debería evitar la descarga de lastre en el puerto.

Palabras clave: Verificación, gestión, tratamiento, agua de lastre

\section{INTRODUCCIÓN}

El agua de lastre, esencial para la operación segura y eficaz de los buques (Hua \& Liu 2008, UNCTAD 2008, Ryan et al. 2013), es a la vez, un factor de riesgo para la bioseguridad marina (Ramírez 2008). Esta es agua de mar que un buque carga en la costa (Minton et al. 2005, Whitman et al. 2011) cuando se encuentra sin o con poca carga para una navegación segura (FMAM-PNUD-OMI 2009). Se define como 'el agua, con las materias en suspensión que contenga, cargada a bordo de un buque para controlar el asiento, la escora, el calado, la estabilidad y los esfuerzos de este' (OMI 2004). No obstante, actúa también como un vector para el traslado accidental de especies entre zonas portuarias (Carlton \& Geller 1993, Carlton 1996, Hay et al. 1997, Ruiz et al. 2000, Murphy et al. 2002, 2004; David et al. 2007, FMAM-PNUD-OMI 2009, Whitman et al. 2011), lo cual puede afectar la biodiversidad y/o generar riesgos a la salud humana por enfermedades o pestes al trasladar también patógenos, todo lo cual puede causar finalmente pérdidas económicas (Ruiz et al. 2000, Doblin \& Dobbs 2006, David et al. 2007, Tamelander et al. 2010, Wonham et al. 2013). 
El tamaño de los organismos (bacterias, microbios, organismos planctónicos en fase adulta y larval, huevos y fases quísticas) presentes en el agua de lastre dependerá de la luz de la rejilla filtradora que cubre la entrada, generalmente de 1 a 2 cm (García \& Fernández 2002, FMAM-PNUDOMI 2009). Un sólo metro cúbico de agua de lastre puede contener hasta 50.000 especímenes de zooplancton (Locke et al. 1991) y/o 10 millones de células de fitoplancton (Subba Rao et al. 1994). Las especies transportadas fuera de su rango de distribución pueden llegar a establecerse y cambiar drásticamente el ecosistema, sus funciones y composición de especies (Hayes \& Sliwa 2003, Molnar et al. 2008). Las especies que logran establecerse y dominar son llamadas especies alienígenas o invasoras (Clinton 1999, Ojaveer et al. 2014), y han sido identificadas como una de las 4 mayores amenazas para los océanos del mundo, causando impactos ambientales, cambios en la función del ecosistema, impactos en la salud y bienestar humana, económicos y culturales (FMAM-PNUD-OMI 2009, Tamelander et al. 2010).

El aumento en la tasa de introducción de especies se atribuye al aumento del comercio a través del océano durante el siglo XX (Carlton 1985, 2001; Ruiz et al. 2000), que se ha visto favorecido con el avance de la tecnología, aumentando la velocidad y frecuencia de los viajes, lo que convierte al agua de lastre en el vector más activo de invasiones marinas (Drake \& Lodge 2004, Hewitt \& Campbell 2007, FMAM-PNUD-OMI 2009, Tamelander et al. 2010). El transporte marítimo es esencial para la economía mundial, cargando mercancías a granel a grandes distancias, con la mejor relación de costo beneficio (Seguí \& Martínez 2004, UNCTAD 2008).

Para reducir los riesgos que genera el agua de lastre, se han adoptado a nivel mundial diversas medidas para regular su carga y descarga, como el Convenio MARPOL $73 / 78$, que hace énfasis en la limpieza de los tanques de lastre, y la Resolución OMI 868 (20) de 1997 (OMI 2004), que considera, siempre que sea posible, efectuar el cambio del agua de lastre por lo menos a 200 millas náuticas de la tierra más próxima y en aguas de $200 \mathrm{~m}$ de profundidad como mínimo (Regla B-4 del Convenio Internacional para el Control y la Gestión del Agua de Lastre y los Sedimentos de los Buques). Así se reemplaza el agua costera que se cargó generalmente en el puerto, de salinidad baja, por agua oceánica de salinidad alta (Minton et al. 2005). La base para adoptar esta medida establece que los organismos costeros al ser expulsados en el agua oceánica mueren por el aumento de salinidad, y lo mismo ocurre con organismos oceánicos al ser vertidos en las aguas del puerto receptor (Brickman $\&$ Smith 2007). Esto reduce significativamente el riesgo de bioinvasión (Hülsmann \& Galil 2001, Minton et al. 2005) ya sea por desplazamiento físico y/o por efectos biocidas (Hülsmann \& Galil 2001). Sin embargo, pese a las medidas tomadas, se estima que el agua de lastre es responsable de la transferencia de 7.000 a 10.000 especies de microbios marinos, plantas y animales a nivel mundial cada día, aunque son pocos los casos confirmados de introducción de especies por esta vía (Carlton 1999). Cuando ha ocurrido, sus consecuencias han sido casi catastróficas e irreversibles, por lo que un enfoque precautorio sugiere que cada buque que transporte agua de lastre debe ser tratado como un riesgo potencial (David \& Perkoviè 2004).

En el marco del enfoque precautorio, resulta imprescindible tener un mayor grado de certeza de la realización efectiva del recambio de agua de lastre en aguas oceánicas. Murphy et al. (2006) mencionan la carencia de una herramienta confiable para determinar si el procedimiento de recambio se llevó efectivamente a cabo. La fiscalización del recambio se basa en la confianza de que se declare lo efectivamente realizado en los documentos (Certificado Internacional de Gestión de Agua Lastre y/o Libro o Plan de Agua de Lastre), presentados por el capitán de buque al administrador o capitán del puerto. Estos documentos contienen datos auto-reportados, y son los únicos utilizados para verificar el cumplimiento del recambio de agua de lastre (Murphy et al. 2013). En el puerto se puede realizar una inspección visual del agua de lastre (OMI 2004); esto resulta inoperante, dadas las eventuales similares características que existen entre el agua de lastre y el agua del puerto receptor, siendo ambas aguas marinas. Un método más efectivo sería contar con una herramienta de gestión que permita verificar el adecuado recambio de agua de lastre, discriminando entre aguas costeras y oceánicas de acuerdo a Murphy et al. (2006). Esta herramienta de gestión debe permitir determinar si existe un riesgo de bioinvasión y debe ser factible de ser aplicada en condiciones prácticas, de tal manera que no interfiera mayormente en la operación normal de un puerto.

Bajo este contexto, se presenta una revisión de los principales factores de riesgo asociados al agua de lastre, de los métodos de cuantificación del riesgo del deslastre y de las herramientas de verificación del recambio de agua de lastre. En base a ello se elabora luego una propuesta de gestión que permita determinar el peligro potencial de la descarga de agua de lastre en puertos de la Ecorregión Marina de Chile Central. 


\section{ELEMENTOS A CONSIDERAR PARA UN PLAN DE GESTIÓN}

\section{NORMATIVA}

El recambio en aguas oceánicas es una medida adoptada por varios países, incluido Chile (Circular A-51/002 - DGTM. Y MM. ORDINARIO N $12.600 / 98)^{1}$, quedando establecido en el Comité de Protección del Medio Ambiente Marino (Res. MEPC 123/53 2005) ${ }^{2}$. El protocolo de recambio en estos puertos es aplicado para naves extranjeras y nacionales, exceptuando a aquellas de cabotaje (DGTM. y MM. N ${ }^{\circ} 12.600 / 982012^{1}$, RES. MEPC.149/55 2006) $)^{3}$. Con esto se da cumplimiento al Párrafo 1, Articulo 142 de La Ley de Navegación Chilena ${ }^{(4)}$ y al Reglamento para el control de la contaminación acuática ${ }^{(5)}$, donde se establece la prohibición absoluta de arrojar lastre, entre otras materias nocivas o peligrosas, de cualquier especie, que ocasionen daños o perjuicios en las aguas sometidas a la jurisdicción nacional, y en puertos, ríos y lagos.

\section{Situación en ChILE}

Con una costa que se extiende por $4.100 \mathrm{~km}(2.600 \mathrm{~km}$ de costa expuesta, desde Arica hasta el Canal de Chacao en Puerto Montt y $1.500 \mathrm{~km}$ de canales y archipiélagos australes) (Ubilla 2011), Chile realiza más del 70\% del comercio exterior por vía marítima desde Arica a Puerto Williams, existiendo actualmente 189 instalaciones portuarias primarias y secundarias de uso comercial (BEAM 2015(6), Ubilla 2011). El territorio marítimo nacional, incluyendo islas oceánicas abarca $3.271 .596 \mathrm{~km}^{2}$ (Ubilla 2011). Sin embargo, la plataforma costera es estrecha, siendo posible encontrar una profundidad de $200 \mathrm{~m}$ dentro de 12 millas náuticas desde la costa.

\section{FACTORES QUE CONDICIONAN EL RIESGO ASOCIADO A LA DESCARGA DE AGUA DE LASTRE}

Las etapas del proceso de invasión biológica son: traslado de una especie fuera de su área de distribución natural, liberación en una nueva localidad, establecimiento de poblaciones autosustentables en esta nueva localidad y expansión de su distribución local más allá del punto inicial de establecimiento (Hallegraeff 1998, Lockwood et al. 2005). Las probabilidades de invasión están fuertemente asociadas a los vectores por medio de los cuales se introducen las especies (Carlton 1996). Generalmente, en zonas costeras las bioinvasiones son producidas por vectores relacionados con actividades humanas (Ruiz et al. 2013). Cuando este vector es el agua de lastre, el componente biológico de la invasión es pobremente comprendido (Keller et al. 2013), puesto que a menudo las especies involucradas no son reconocidas sino hasta que se establecen (Carlton 1996, Minton et al. 2005). Luego, si la especie sobrevive a la toma de lastre, al viaje y al deslastre (Hallegraeff 1998), será una especie exótica de características resistentes al stress que puede llegar a causar impactos económicos, ecológicos o sanitarios en el nuevo ambiente (Hallegraeff 1998, Lockwood et al. 2005).

El proceso de bioinvasión depende de factores tales como la presión de propágulo y el ajuste climático (Ziller et al. 2007), que consideran que el éxito de la bioinvasión está fuertemente relacionado con las coincidencias ambientales, las características de la biota y las dinámicas de inoculación (Whitman et al. 2011). Bajo este contexto, los factores de riesgo asociados a la descarga de agua de lastre son: el volumen y frecuencia de las descargas de agua de lastre, la similitud ambiental entre los puertos de origen (puerto donante) y los puertos de destino (BWRA 2003, Mallmann \& Asmus 2006, FMAM-PNUD-OMI 2009) y la presencia de especies de riesgo en la bio-región del puerto donante (Mallmann \& Asmus 2006). También es importante considerar el tamaño o capacidad del tanque de lastre y el tiempo de confinamiento del lastre o tiempo de viaje del buque (BWRA 2003, Mallmann \& Asmus 2006). Estos son los factores considerados en las evaluaciones de riesgo piloto implementadas por el Programa Globallast, desarrollado en conjunto por la Organización Marítima Internacional (OMI), junto con el Fondo Mundial del Medio Ambiente (GEF), el Programa de Desarrollo de Naciones Unidas (PNUD),

${ }^{1}$ DIRECTEMAR. 2012. Resolución DGTM. y MM. Ordinario N²12.600/98 Circular A-51/002 con fecha 24 de Enero de 2012,9 pp. Dirección General del Territorio Marítimo y de Marina Mercante, Valparaíso.

${ }^{2}$ RESOLUCIÓN MEPC. 123 (53). 2005. Directrices para el cumplimiento equivalente de la gestión del agua de lastre (D3) con fecha 22 de Julio de 2005 'Adopta las Directrices para el cumplimiento equivalente de la gestión del agua de lastre', 4 pp.

${ }^{3}$ RESOLUCIÓN MEPC. 149 (55). 2006. Directrices para el cambio del agua de lastre (normas de proyecto y construcción) (D11) con fecha 13 de Octubre de 2006 'Adopta las Directrices para el cambio del agua de lastre', 6 pp.

${ }^{4}$ DIRECTEMAR. 2005. Decreto de Ley 2222, Ley de Navegación con fecha 09 de Diciembre de 2005, 44 pp. Dirección General del Territorio Marítimo y de Marina Mercante, Valparaíso.

${ }^{5}$ D.S. № 1/1992. Reglamento para el control de la contaminación acuática, 30 pp. Ministerio de Defensa Nacional, Santiago.

${ }^{6}$ BEAM. 2015. Boletín Estadístico Marítimo. Armada de Chile, DIRECTEMAR, 227 pp. DIRECTEMAR, Armada de Chile, Valparaíso. <http://web.directemar. cl/estadisticas/maritimo/2016/BEAM2016.pdf> 
con el fin de apoyar a los países interesados en reducir la transferencia de organismos bioinvasores transportados en las aguas de lastre. El riesgo potencial de la descarga de agua de lastre en un determinado puerto receptor es proporcional al aumento de cada factor de riesgo (Mallmann \& Asmus 2006), siendo sin embargo la frecuencia de la descarga y la similitud ambiental entre el puerto de origen y el puerto de destino los más importantes (FMAM-PNUD-OMI 2009). Es importante tener una comprensión de todos los factores (Tamelander et al. 2010), por lo que a continuación se presentan los fundamentos teóricos que explican el riesgo potencial implícito en cada uno de ellos:

El Volumen y Frecuencia de la descarga del agua de lastre inciden mayormente en la 'presión de propágulos' o 'esfuerzo de introducción', conceptos importantes en el manejo del agua de lastre (Ruiz et al. 2000, Minton et al. 2005, Verling et al. 2005, Costello et al. 2007) y que representan una medida del número de individuos no nativos liberados en una región (Lockwood et al. 2005, Lee et al. 2013). El número total o abundancia de individuos en cada invasión se denomina 'tamaño del propágulo' y el número o frecuencia de eventos de liberación, desde un mismo origen se denomina 'número de propágulos', (Verling et al. 2005, Johnston et al. 2009, Ricciardi et al. 2010). En el caso del agua de lastre, el tamaño del propágulo corresponde al volumen de la descarga, y el número de propágulo a la frecuencia de la descarga o de inoculación desde un mismo puerto donador (Clarke et al. 2003). Al incrementarse cualquiera de estos componentes, aumenta la presión de propágulo (Lockwood et al. 2005, Mendoza-Alfaro \& Koleff-Osorio 2014), aumentando por consiguiente la probabilidad de éxito de la invasión (Ruiz et al. 2000, Leung et al. 2004, Van Holle \& Simberloff 2005, Ruesink 2005, Colautti et al. 2006), puesto que la probabilidad de establecimiento de una especie incrementa en función del tamaño de la inoculación (Ruiz et al. 2000).

El Tamaño del tanque de agua de lastre influye en el éxito de la invasión biológica (Minchin \& Gollasch 2003, Verling et al. 2005). En tanques de lastre de mayor tamaño la disminución de los niveles de oxígeno y la calidad del agua ocurre a tasas más lentas (Oemcke 1998). Por lo tanto, mientras menor sea el tamaño del tanque de lastre, menor será el riesgo potencial de invasión biológica.

La Duración del viaje influye en la sobrevivencia de los organismos, pues luego de viajes largos, la variedad de especies sobrevivientes que se pueden encontrar en el tanque de lastre es baja (Gollasch \& Leppäkoski 2007), debido a la ausencia de luz y la pérdida de la calidad de agua, especialmente por la disminución de los niveles de oxígeno y $\mathrm{pH}$, por el efecto de la respiración biológica y la oxidación de hierro (Clarke et al. 2003). El efecto del tiempo de viaje se evidencia incluso en períodos de viaje relativamente cortos (5 días), en los cuales declina notoriamente la densidad planctónica (Oemcke 1998). Períodos de viaje más largos (> 20 días) causan la mortalidad de diversos estados planctónicos de distintas especies (Clarke et al. 2003).

La Similitud ambiental entre región donadora y región receptora ayuda a aumentar la probabilidad de éxito de una invasión biológica en nuevos ambientes (FMAM-PNUDOMI 2009) traspasando barreras geográficas y provocando una homogenización de la biota del planeta (Sala et al. 2000, Mendoza-Alfaro \& Koleff-Osorio 2014). En general, mientras mayor sea la similitud ambiental entre el puerto donador y el receptor, mayor será la probabilidad de éxito de la invasión biológica (Carlton 1985, Carlton \& Geller 1993, Hedgpeth 1993, Gollasch 1996).

Los organismos que pueden sobrevivir en un nuevo ambiente acuático son relativamente pocos, ya que la temperatura, el alimento o la salinidad suelen resultar limitantes (Carlton \& Geller 1993). En el caso del agua de lastre los principales factores ambientales que determinan el éxito de la invasión biológica son: los límites superior e inferior de su temperatura y la tolerancia a la salinidad en relación con las del puerto, el período de tiempo en el que la temperatura ambiente es favorable para la reproducción, la presencia de otras condiciones ecológicas adecuadas, por ejemplo, el hábitat, los depredadores y las fuentes de alimentos (Tamelander et al. 2010). Cabe destacar que los ambientes estresados por acción antrópica son más fácilmente colonizados por especies exóticas (Occhipinti \& Savini 2003). En este contexto, comprender la relación entre los efectos antrópicos y/o las perturbaciones naturales con el desarrollo masivo de especies no autóctonas, ayudará a prevenir invasiones biológicas marinas favorecidas por el transporte de especies incrustadas en los cascos de los buques o vía agua de lastre (Carlton 1985, Carlton \& Geller 1993, Wonham et al. 2000, Whitman et al. 2011, Ruiz et al. 2013).

De acuerdo a las diferentes características ambientales, geográficas y ecológicas, las costas del mundo se pueden dividir en ecorregiones, que corresponden a ensambles geográficos definidos, constituidos por comunidades naturales que comparten la mayoría de sus especies, la dinámica ecológica de las condiciones ambientales y cuyas interacciones ecológicas son típicas para su persistencia a largo plazo (Dinerstein et al. 1995). En el presente estudio se ha definido como región receptora de agua de lastre a la zona costera frente a la ciudad de Coquimbo, zona de aguas frías, pero que recibe una alta radiación solar, tiene marcadas fluctuaciones de temperatura invierno-verano y día-noche, las precipitaciones son escasas y predominan los vientos del suroeste que provocan surgencias costeras (CONAMA 2008). Esta zona es denominada Ecorregión Marina de Chile Central, se extiende desde Antofagasta $\left(25^{\circ} \mathrm{S}\right)$ a Valparaíso $\left(33^{\circ} \mathrm{S}\right)$ (Valenzuela 2013). Para definir las zonas costeras similares a Coquimbo se utilizó el mapa 
de ecorregiones de Spalding et al. (2007), donde clasifican a las distintas regiones costeras del mundo en diferentes 'reinos', los que están divididos en 'provincias' y estas a su vez en 'ecorregiones marinas', estando la Ecorregión Marina de Chile Central dentro de la provincia marina del Pacífico Sureste Templado Cálido, reino Sur América Templado. De acuerdo a Spalding et al. (2007) en el mundo existen 232 ecorregiones marinas, distribuidas en 25 provincias y 5 reinos, de las cuales 80 son de características templadas, que por lo tanto, tendrían características similares a la Ecorregión Marina de Chile Central, por lo que el agua de lastre proveniente de todas ellas representaría un mayor peligro potencial de éxito de la invasión biológica para la zona costera de Coquimbo.

\section{Presencia de especies nocivas en la Región DONADORA Y QUE PUDIERAN TENER POTENCIAL INVASOR}

Las especies invasoras pueden ser clasificadas según el impacto que causan, en especies no nocivas, potencialmente nocivas y reconocidamente nocivas (Mallmann \& Asmus 2006). Dentro de las especies reconocidamente nocivas están las llamadas Floraciones Algales Nocivas (FAN). La mayoría de los organismos causantes de FAN pueden formar quistes (Sar et al. 2002). Avaria et al. (1999) estiman que el transporte de quistes de dinoflagelados en aguas de lastre de los buques, entre otros, podría haber provocado un incremento en la frecuencia, intensidad y permanencia de las FAN en diversas áreas costeras, así como también un incremento en su cobertura geográfica y distribución mundial.

El riesgo de que una invasión genere impacto en el lugar receptor, es más alto, mientras más especies potencial o reconocidamente nocivas hay en la región donadora. Cuando esa especie nociva se ha catalogado como invasora en el lugar donante, el riesgo resulta mayor (BWRA 2003, Clarke et al. 2003, Mallmann \& Asmus 2006).

En el Programa Globallast (<http://globallast.imo.org/>) existen bases de datos de especies invasoras en el Mar Báltico, Mar Mediterráneo, Australia, aguas Británicas y algunas áreas de Estados Unidos. Además, se encuentra un resumen de la distribución de las diez especies invasoras más temidas a nivel global, ya que han invadido las seis áreas monitoreadas por el Programa Globallast y que por lo tanto podrían considerarse como especies con un alto grado de adaptación a cualquier medio ambiente marino al cual lleguen (Ubilla 2011). Como las FAN están definidas como especies reconocidamente nocivas, su distribución global se investigó en más detalle en la página web del programa GEOHAB (Global Ecology and Oceanography of Harmful Algal Blooms) ${ }^{7}$ de la UNESCO, que presenta la distribución global de diferentes venenos o toxinas provenientes de las FAN.

\section{Zonas Potencialmente Peligrosas (ZPP)}

Puesto que en las zonas costeras de características templadas, es frecuente la presencia de FAN (Taylor et al. 2007) y que el número de especies invasoras marinas aumenta con la latitud, es decir, es mayor en zonas templadas (Tamelander et al. 2010), se identificó en el mapa de ecorregiones marinas de Spalding et al. (2007) aquellas zonas con presencia de especies de riesgo y que además presentan similitud ambiental con la Ecorregión Marina de Chile Central (Fig. 1). La descarga de agua de lastre en la Ecorregión Marina de Chile Central desde cualquiera de estas zonas representa un mayor riesgo, por lo que se denominaron como Zonas Potencialmente Peligrosas (ZPP).

\section{CUANTIFICACión DEL RIESgo ASOCIADO A CADA DESCARGA DE AGUA DE LASTRE}

El Programa Global de Manejo de Agua de Lastre (Programa Globallast) propone cuantificar el riesgo asociado a la descarga de agua de lastre, calculando el Riesgo Relativo Global (ROR por sus siglas en inglés) (BWRA 2003). Esta es la medida combinada de cada uno de los factores de riesgo asociados a la descarga de agua de lastre. En este trabajo se reemplazará la sigla ROR por CRG, que significa Coeficiente de Riesgo Global.

Cuatro de los factores de riesgo asociados al agua de lastre, son denominados como coeficientes primarios $(\mathrm{C} 1$, C2, C3 y C4). En términos biológicos, C1 y C2 representan la frecuencia y el tamaño de la inoculación, respectivamente, C3 proporciona una medida de la probabilidad de sobrevivencia de estos organismos inoculados, y C4 la amenaza relativa planteada por los organismos dentro de cada inoculación (BWRA 2003, Clarke et al. 2003).

Esta metodología fue desarrollada por Clarke et al. (2003) y por Mallmann \& Asmus (2006), tal como lo establece el Programa Globallast y con algunas modificaciones por Brickman (2006) y por Brickman \& Smith (2007).

${ }^{7<h t t p: / / w w w . w h o i . e d u / r e d t i d e />~}$ 


\section{CÁlCULO de COEFICIENTES DE RIESGo PRIMARIO}

Los coeficientes primarios $\mathrm{C} 1$ y $\mathrm{C} 2$ se calculan de acuerdo a las indicaciones del Programa Globallast. Los coeficientes primarios $\mathrm{C} 3$ y $\mathrm{C} 4$ fueron adaptados para aprovechar la información existente.

C1: frecuencia relativa del número de tanques de lastre provenientes de un mismo puerto $(f i)$ en relación al número total de tanques descargados en un año (N). Valor de 0 a 1.

$$
\mathrm{C} 1=\frac{f i}{N}
$$

C2: proporción del volumen de agua de lastre de un determinado puerto de origen $(\mathrm{A})$ en relación al volumen total descargado en un año (B). Su valor va de 0 a 1 .

$$
\mathrm{C} 2=\frac{\mathrm{A}}{\mathrm{B}}
$$

C3: este coeficiente se refiere a la similitud ambiental entre los puertos donadores y el receptor. El programa Globallast realiza un cálculo de matrices ambientales para determinar la similitud entre puertos. La magnitud de este factor varía entre 0,05 a 1 . No se considera el 0 como valor mínimo ya que no se puede asumir que un puerto es completamente diferente de otro. En esta propuesta, se realizó una adaptación con la información existente sobre la similitud ambiental entre diferentes ecorregiones marinas del mundo, jerarquizando las zonas globales en: Zonas muy similares ambientalmente $(\mathrm{C} 3=1)$, Zonas similares ambientalmente $(\mathrm{C} 3=0,5)$ y Zonas sin similitud ambiental conocida $(\mathrm{C} 3=0,05)$. Estas zonas fueron definidas de acuerdo al mapa de ecoregiones marinas de Spalding et al. (2007). Como la ecorregión marina de Chile Central se ubica en la provincia marina Cálida Templada del Pacífico Sureste, se definen como ecorregiones 'muy similares' todas aquellas que se encuentran en provincias marinas cálidas templadas y como 'similares' a todas aquellas que se encuentran en reinos de características templadas, pero que no están en una provincia cálida. En la Figura 2 se resume la información para determinar el valor de C3.

C4: medida de riesgo presentado por cada puerto donador debido al número de especies presentes en la biorregión categorizadas como introducidas (I), potencialmente nocivas $(\mathrm{P})$ o reconocidamente nocivas $(\mathrm{N})$. De acuerdo

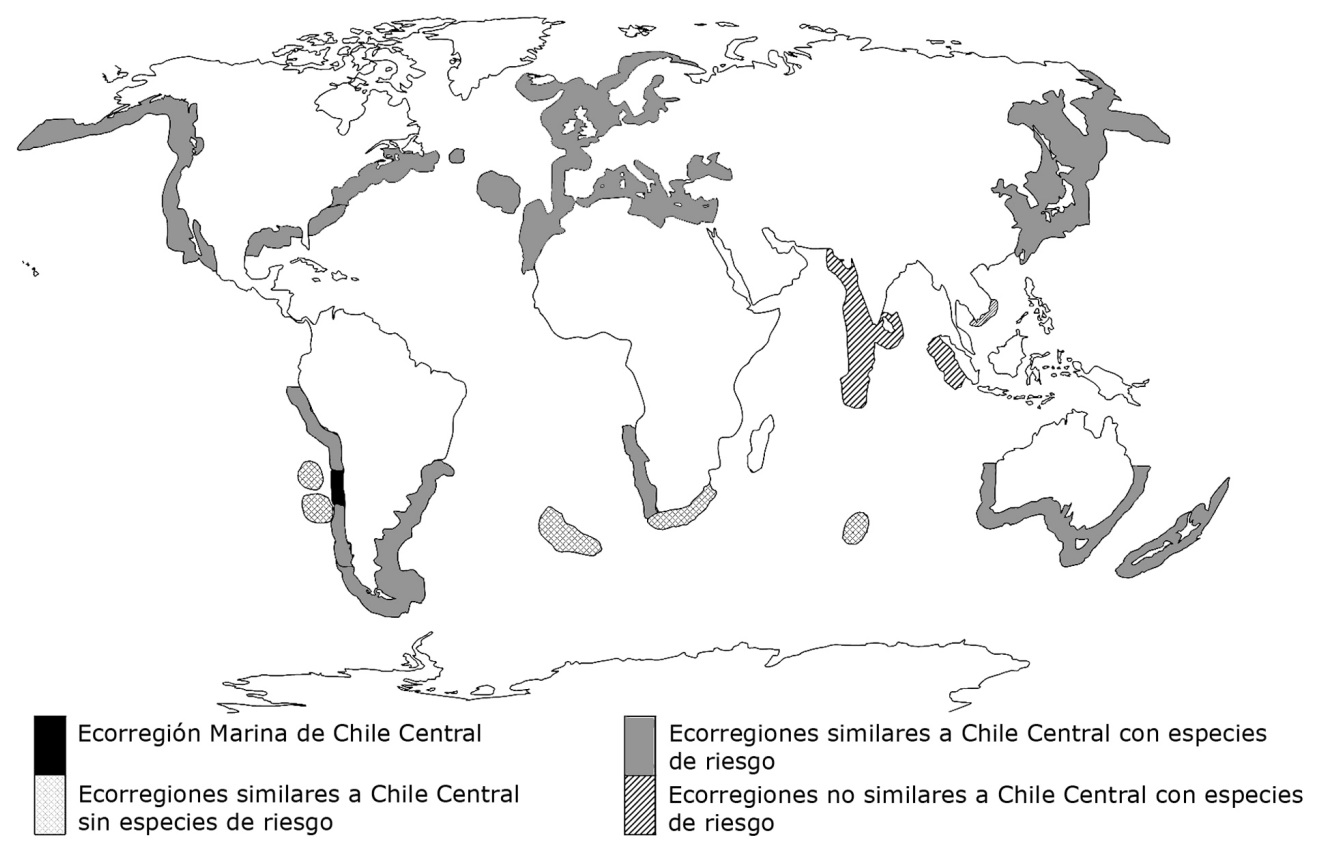

Figura 1. Zonas de procedencia de agua de lastre Potencialmente Peligrosas (ZPP) para la ecorregión marina de Chile Central. Información basada en la similitud ambiental y en la presencia de especies de riesgo. Figura modificada de Spalding et al. (2007) / Areas of origin of Potentially Dangerous ballast water (ZPP) for marine ecoregion of central Chile. Information based on environmental similarity and the presence of species at risk. Modified figure of Spalding et al. (2007) 
al Programa Globallast, cada categoría tiene un peso diferente en el cálculo de este coeficiente. La sumatoria de todas estas especies se divide por número total de especies de riesgo en las biorregiones de todos los puertos donadores (NT), obteniendo un valor entre 0 a 1 . Para calcular $\mathrm{C} 4$, en la presente propuesta, se asume que no hay especies potencialmente nocivas, sino que solo hay especies introducidas y reconocidamente nocivas, con esto se disminuye el error de clasificación de las especies. De esta manera, la fórmula para calcular este coeficiente es:

$$
\mathrm{C} 4=\frac{[\mathrm{I}+10 \mathrm{~N}]}{\mathrm{NT}}
$$

Para esta propuesta, el riesgo se acotó a la presencia de las diez especies mencionadas por el Programa Globallast como reconocidamente nocivas y a la información sobre especies alienígenas proporcionada en un censo de la biodiversidad marina realizado por Costello et al. (2010). Esta información se resume en la Tabla 1.
CUANTIFICACIÓN DEL RIESGO POTENCIAL DE UNA Descarga de AgUa de lastre a Partir del Coeficiente de Riesgo Global

Una vez que han sido calculados los coeficientes de riesgo primario se traspasan los valores a la ecuación para el cálculo del Coeficiente de Riesgo Global (CRG) o Relative Overall Risk (ROR), que considera dos factores de reducción de riesgo: tamaño del tanque de lastre (R1) y tiempo de navegación (R2) (BWRA 2003, Clarke et al. 2003). Estos dos valores deben ser obtenidos del Reporte de Agua de Lastre, además el tiempo de navegación (R2) puede ser corroborado revisando el 'Port of Call List'. Estos documentos deben ser proporcionados por el capitán del buque al administrador del puerto.

En términos biológicos, $\mathrm{R} 1$ es el efecto del tamaño del tanque de lastre sobre el volumen de la descarga (C2), de la cual depende la calidad del agua en cuanto a oxígeno, $\mathrm{pH}$, entre otros parámetros físico-químicos. R2 es el efecto del tiempo de almacenamiento en el tanque sobre la sobrevivencia de los organismos, y actúa sobre C4. La magnitud de ambos factores fue predefinida en BWRA (2003) (Tabla 2).

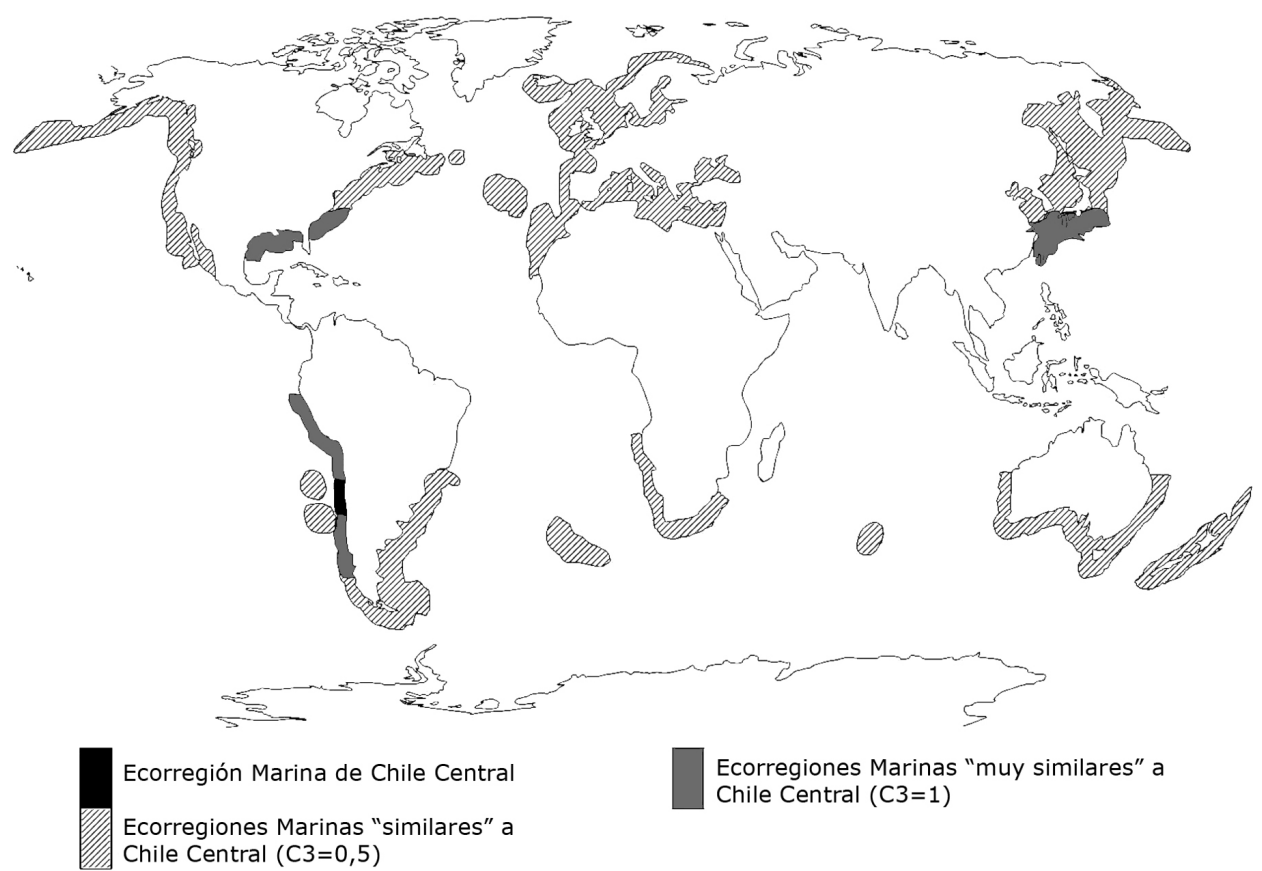

Figura 2. Esquema de jerarquización de riesgo de las zonas de procedencia de agua de lastre de acuerdo al grado de similitud ambiental con la zona costera de Coquimbo. Aquellas ecorregiones coloreadas en gris tienen un $C 3=1$ y aquellas achuradas con blanco y negro tienen un $C 3=0,5$. Las ecorregiones no coloreadas en este mapa tienen un C3=0,05. Figura modificada de Spalding et al. (2007) / Prioritization scheme risk areas of origin of ballast water according to the degree of environmental similarity to the coastal area of Coquimbo. Those ecoregions colored in gray have a C3 $=1$ and those with black and white have a C3=0.5. The uncolored ecoregions on this map have a C3=0.05. Modified figure of Spalding et al. (2007) 
Tabla 1. Número de especies de introducidas por región marina (Fuente Costello et al. 2010) y número de especies reconocidamente nocivas (Programa Globallast). La presencia de FAN es considerada como una única especie / Number of species introduced by marine region (Costello et al. 2010) and number of recognizably harmful species (Globallast Program). The presence of FAN is considered a single species

\begin{tabular}{lccl}
\hline \multirow{2}{*}{ Región marina } & \multicolumn{3}{c}{ Categoría de especie } \\
\cline { 2 - 4 } & $\begin{array}{c}\text { Introducidas } \\
\text { (I) }\end{array}$ & \multicolumn{1}{c}{ Nocivas (N) } \\
\cline { 3 - 4 } Mediterráneo & 637 & 2 & FAN, abeto marino \\
Europa atlántica & 245 & 4 & $\begin{array}{l}\text { Mejillón zebra, abeto marino, cangrejo verde } \\
\text { europeo, FAN }\end{array}$ \\
Nueva Zelanda & 157 & 2 & FAN, abeto marino \\
Australia & 128 & 4 & $\begin{array}{l}\text { Abeto marino, cangrejo verde europeo, estrella de } \\
\text { mar del Pacífico norte, FAN }\end{array}$ \\
Báltico & 117 & 5 & Mejillón zebra, abeto marino, cangrejo verde \\
Sur África & 83 & 2 & FAN, cangrejo verde europeo \\
Corriente de Humbolt & 77 & 2 & FAN, cólera \\
Caribe & 45 & 0 & \\
Japón & 36 & 2 & FAN, cangrejo verde europeo \\
Plataforma patagónica & 33 & 2 & Cólera, abeto marino \\
China & 16 & 1 & FAN \\
Pacífico este tropical & 15 & 0 & \\
Pacífico oeste tropical & 11 & 0 & \\
Alaska & 0 & 1 & FAN \\
Oeste de Canadá & 0 & 1 & FAN \\
California & 1577 & & FAN \\
Total (NT) & & & \\
\hline & & &
\end{tabular}

Tabla 2. Magnitud de los factores de reducción de riesgo. Fuente BWRA User Guide (2003) / Magnitude of risk reduction factors. Source BWRA User Guide (2003)

\begin{tabular}{lccccc}
\hline \multicolumn{5}{c}{ Tamaño del tanque de lastre (R1) } \\
\hline Capacidad del tanque de lastre (ton) & $<100$ & $100-500$ & $500-1.000$ & 1.000 \\
R1 & 0,4 & 0,6 & 0,8 & 1,0 \\
\hline \multicolumn{7}{c}{ Tiempo de viaje (R2) } \\
\hline T (días) & $<5$ & $5-10$ & $10-20$ & $20-50$ & $>50$ \\
R2 & 1 & 0,8 & 0,6 & 0,4 & 0,2 \\
\hline
\end{tabular}

Conociendo entonces la magnitud de los coeficientes primarios y de los factores de reducción de riesgo, se puede calcular el coeficiente de riesgo global (CRG) asociado a la descarga de agua de lastre de cada buque que arriba al puerto receptor. Se divide por 4 para mantener el resultado en un rango entre 0 y 1 , luego se multiplica por 100 , para expresar el CRG como una tasa o porcentaje del riesgo. De esta manera se conoce el porcentaje de riesgo asociado a la descarga de agua de lastre $(\% \mathrm{R})$ :

$$
\begin{gathered}
\mathrm{CRG}=\frac{\mathrm{C} 1+(\mathrm{C} 2 * \mathrm{R} 1)+\mathrm{C} 3+(\mathrm{C} 4 * \mathrm{R} 2)}{4} \\
\% \mathrm{R}=\mathrm{CRG}^{*} 100
\end{gathered}
$$

Este porcentaje se compara con los porcentajes de probabilidad de ocurrencia del riesgo, propuestos por Tapia et al. 2013 (Tabla 3). Si \%R es mayor a 16\% la descarga de agua de lastre representa un peligro potencial para el puerto receptor. Para todos aquellos barcos que arriban al puerto que tengan un $\% \mathrm{R}$ sobre $16 \%$ se debe verificar si efectivamente se realizó el recambio de agua en mar abierto. 
Tabla 3. Escala de Probabilidades de Ocurrencia del Riesgo, según Distribución Normal. (Fuente: Tapia et al. 2013) / Occurrence Probability Scale Risk, according to Normal Distribution. (Source: Tapia et al. 2013)

\begin{tabular}{lccccc}
\hline \multicolumn{5}{c}{ Ocurrencia } \\
\hline Probabilidad & Improbable & Poco probable & Probable & Muy probable & Certeza \\
Porcentaje & $\leq 2 \%$ & $2,1-16 \%$ & $16,1-50 \%$ & $50,1-85 \%$ & $>85 \%$ \\
\hline
\end{tabular}

\section{Procedimiento para Verificar el Recambio de AGUA DE LASTRE}

Las principales investigaciones respecto a la verificación del cumplimiento del recambio del agua de lastre han sido realizadas por el Laboratorio de Investigación de Invasiones Marinas del Centro Smithsoniano de Investigación Ambiental (SERC, por sus siglas en inglés) ${ }^{8}$, siendo la materia orgánica cromofórica disuelta (CDOM) el parámetro que mejor se ajusta a esta propuesta. Al respecto, Murphy et al. (2013) señalan que la medición de CDOM es un buen indicador del recambio de agua de lastre, pudiéndose relacionar directamente con la salinidad. Los niveles de CDOM son menores en aguas oceánicas $(>100$ $\mathrm{nmi}=<0,6$ QSE), respecto a aguas costeras $(<0,2 \mathrm{nmi}=>0,8$ QSE), esta diferencia permitiría verificar la ocurrencia del recambio de agua de lastre, mediante un muestreo.

\section{Propuesta Plan de Gestión Preventivo}

El riesgo potencial asociado a la descarga de agua de lastre es diferente en cada buque que arriba a un puerto receptor, ya que está sujeto a la variación de los factores de riesgo asociados al agua de lastre, por lo tanto, se propone la implementación del siguiente plan de Gestión de agua de lastre por parte de los buques que arriben a Puerto:

\section{Conformidad con el Reporte de Agua de LASTRE}

-Cuando el buque arriba al Puerto debe traer consigo un Libro de Agua de Lastre y un Reporte de Agua de Lastre. El Reporte de Agua de Lastre debe ser llenado y firmado por el capitán del buque y se debe verificar, tal como se señala en la Figura 3, que contenga la información que solicita en la Tabla 4.

\footnotetext{
${ }^{8}<$ http://www.serc.si.edu/labs/>
}

-Si la información contenida en estos documentos es inexistente, poco clara o no conforme, el buque no podrá realizar la operación de deslastrado y deberá volver a aguas oceánicas a realizar la operación de recambio (Fig. 3).

-Si la información contenida en estos documentos es clara o conforme, se verifica si el Reporte de Agua de Lastre señala que se efectuó el Recambio de Agua de Lastre (BWE).

-Si esto no está señalado, se verificara si se señala haber efectuado algún tratamiento biocida a bordo. Si no existe recambio de agua de lastre, ni tratamiento de esta, el buque no puede deslastrar y deberá volver a aguas oceánicas a realizar la operación de recambio (Fig. 3).

-Si el Reporte de Agua de Lastre indica que se efectuó el recambio de agua de lastre y/o un tratamiento biocida a bordo, se debe continuar con la siguiente etapa del plan de gestión (Fig. 3).

\section{Primera Evaluación de Riesgo: Verificar la(s) ZONA(S) DE PROCEDENCIA DEL AGUA DE LASTRE}

-Se solicitará al capitán del buque el documento 'Port of Call List', donde se identifica el último puerto donde el buque realizó maniobras de descarga de material, ya que en este puerto el buque debió obligatoriamente cargar agua de lastre. Como medida precautoria se asume como procedencia del agua de lastre al puerto donador previo a la etapa de recambio de agua de lastre, por lo que la estimación de cada factor de riesgo se basa en la información sobre el agua de lastre de estos puertos. La información de este documento debe también señalar las fechas de carga y descarga de material, información necesaria para determinar el tiempo de viaje o de confinamiento del agua de lastre.

-Si la información del 'Port of Call List' señala que el último puerto de descarga de material está fuera de los sectores costeros definidos previamente, en la Fig. 1, como Zonas Potencialmente Peligrosa (ZPP), el buque puede deslastrar. Este buque puede también pasar a un sistema de muestreo al azar, que se puede realizar en forma paralela al deslastre, donde se medirá el contenido de sustancias contaminantes (por ej. sustancias oleosas) en el agua de lastre. Los resultados de este muestreo serán contrastados 


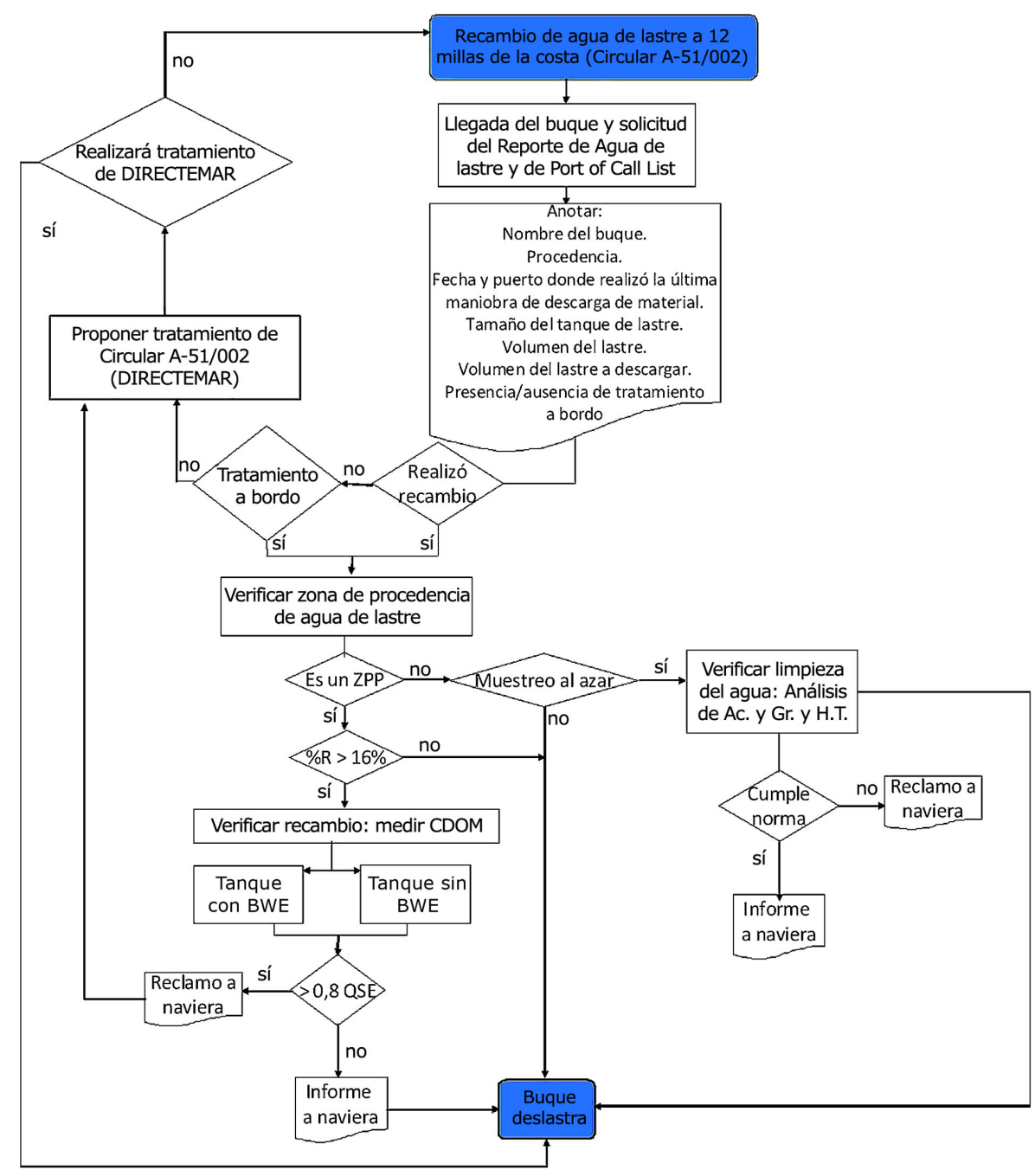

Figura 3. Diagrama de flujo: Plan de gestión preventivo para el riesgo de contaminación biológica vía agua de lastre. CDOM y BWE son abreviaciones en inglés de Materia Orgánica Cromofórica Disuelta y Recambio de Agua de Lastre, respectivamente / Flowchart: preventive management plan for the risk of biological contamination via ballast water. CDOM and BWE correspond to the abbreviations of Chromophoric Dissolved Organic Matter and Ballasts Water Exchange, respectively

Tabla 4. Información que se debe obtener del reporte de agua de lastre / Information to be obtained from the ballast water report

\begin{tabular}{l}
\hline Información que debe estar presente en el reporte de agua de lastre \\
\hline Nombre de buque \\
Procedencia \\
Puertos o coordenadas de carga de agua de lastre \\
Identificación (con número, nombre o letra) de los tanques de lastre o de bodegas cargados con lastre en cada puerto donador \\
Volumen cargado en cada tanque o bodega en cada puerto donador \\
Identificación (con número, nombre o letra) de los tanques de lastre o de bodegas que serán deslastradas en el puerto receptor \\
Volumen que será deslastrado desde cada tanque o bodega en el puerto receptor \\
Tamaño o capacidad del/los tanques de lastre que se descargaran \\
Presencia y ejecución de tratamiento biocida a bordo para el agua de lastre \\
\hline
\end{tabular}


con la normativa nacional vigente (D.S. 1/1992) $)^{5}$ y serán informados a la empresa portuaria (Fig. 3).

-Si la información del 'Port of Call List' señala que el último puerto de descarga de material está en algún sector costero señalado en Fig. 1 como una ZPP se continúa con la segunda evaluación de riesgo del plan de gestión (Fig. 3).

\section{Segunda Evaluación de Riesgo: cuantificar EL RIESGo ASOCIADO A LA DESCARGa DEL AGUA DE LASTRE}

-Con la información del Reporte de Agua de Lastre y el Port of Call List, se debe calcular los Coeficientes de Riesgo Primario C1 y C2, y se debe determinar la magnitud de los Factores de Reducción de Riesgo R1 y R2. Con la información proporcionada en la Fig. 2 se estimará el Coeficiente de Riesgo Primario C3. Con la información proporcionada en la Tabla 1 se estimará el Coeficiente de Riesgo Primario C4. Con la información de la Tabla 2 se estiman R1 y R2.

-Una vez conocida la magnitud de cada Coeficiente de Riesgo Primario y de cada Factor de Reducción de Riesgo, se reemplazarán los valores en la fórmula de Coeficiente de Riesgo Global (CRG), que será multiplicado por 100 para obtener un Porcentaje de Riesgo $(\% \mathrm{R})$ que se asociará la descarga de agua de lastre:

-Si $\% \mathrm{R} \leq 16$, el riesgo es poco probable y el buque puede deslastrar (Tabla 3, Fig. 3). Si \%R > 16\%, la ocurrencia de riesgo comienza a ser probable, por lo que se debe continuar con la siguiente etapa de evaluación de riesgo (Tabla 3; Fig. 3).

\section{Tercera Evaluación de Riesgo: chequear el RECAMBIO DE AGUA DE LASTRE}

Una vez que se determina que la descarga de agua de lastre representa un riesgo para el puerto receptor, se deberá realizar un muestreo para verificar que se haya efectuado el del agua de lastre en aguas oceánicas. Esto se llevará a cabo siguiendo las Directrices Para el Muestreo de Aguas de Lastre (D2) de la Resolución MECP 173(58)/2008 ${ }^{(9)}$. Se utilizará un fluorómetro portátil para medir la cantidad de Materia Orgánica Cromofórica Disuelta (CDOM).

-Si el resultado de la medición es $<0,8$ QSE, indica que el agua de lastre tiene características oceánicas, lo que implica que se efectuó el recambio de agua de lastre, dando cumplimiento a la regla B-4 de la directriz internacional (Fig. 3).

\footnotetext{
${ }^{9}$ RESOLUCIÓN MEPC. 173 (58). 2008. Directrices para el muestreo del agua DE (D2) con fecha 10 de Octubre de 2008 'Adopta las Directrices para el muestreo del agua de lastre', 16 pp.

${ }^{10}$ Bermúdez J. 2011. Análisis de la legislación internacional y chilena Sobre gestión de las aguas de lastre y propuesta de modificación. Informe Consultor Jurídico, Valparaíso, 44 pp.
}

-Si el resultado de la medición es $>0,8$ QSE, indica que el agua de lastre tiene características portuarias o cercanas a un puerto, lo que implica que no se efectuó el recambio de agua de lastre, por lo que el buque debería realizar el tratamiento que especifica la Circular A-51/002(1). Esto significa que se deben aplicar $11 \mathrm{~g}$ de Hipoclorito de Sodio en polvo o $14 \mathrm{~g}$ de Hipoclorito de Calcio en polvo por tonelada de agua de lastre a cada tanque que deslastrará. Este proceso debe ser realizado a lo menos 4 horas antes de iniciar el deslastrado (Fig. 3).

-Si el buque realiza el tratamiento puede deslastrar (Fig. $3)$.

-Si el buque no realiza el tratamiento debe regresar a aguas oceánicas a realizar la maniobra de recambio de agua lastre (Fig. 3).

-Los resultados de esta medición serán comunicados a la empresa portuaria mediante un informe escrito (Fig. 3). Si existiesen dudas respecto a los resultados, estos podrán ser corroborados (de ser posible) tomando muestras de agua desde estanques en los que no se haya efectuado el recambio de agua de lastre. En los que se deberían detectar niveles de $\mathrm{CDOM}>0,8$ QSE. Si los niveles detectados no son los esperados se deberá repetir la $3^{\circ}$ Etapa de Evaluación de Riesgo.

\section{DisCUSIÓN}

El manejo del agua de lastre es un tema complejo que plantea como desafío fusionar regulaciones internacionales, soluciones técnicas y la conservación ecológica (Endresen et al. 2004). En ese contexto se requiere de una propuesta simple, como la que plantea este trabajo, como aporte. La lentitud de la entrada en vigor de las regulaciones internacionales, promueve el desarrollo de propuestas regionales para cumplir demandas locales (Endresen et al. 2004). En Chile, la normativa referente al tema se restringe a la Circular A 51/002 ${ }^{(1)}$, instrumento de baja jerarquía, incapaz de otorgar una protección adecuada al respecto (Bermúdez 2011) ${ }^{10}$. Esta circular considera el recambio de agua de lastre para naves extranjeras y nacionales, pero excluye a las naves de cabotaje (DGTM. Y MM. ORDINARIO $\left.N^{\circ} 12.600 / 982012\right)^{1}$, probablemente debido a las limitaciones operacionales que impiden realizar el recambio en cortos períodos de viaje y/o con mar agitado (Lee et al. 2013). A la vez, excluye también a aquellos buques graneleros, quimiqueros y gaseros que provengan de puertos nacionales libres de FAN. Los buques graneleros son los que predominan en el país (BEAM 2015) ${ }^{6}$, por lo tanto, al excluir a estas naves se deja de considerar un gran volumen de agua de lastre. A continuación se analizan las implicancias de cada etapa propuesta para el desarrollo de este plan de gestión propuesto. Existen diversos tratamientos para minimizar el riesgo de introducción de especies en el proceso de deslastre (Matheickal et al. 2004, Bellefontaine et al. 2010, Ubilla 2011). No obstante, aún con múltiples tratamientos, la eliminación completa de la biota en el agua 
de lastre en un futuro próximo es improbable, por lo que la principal medida continua siendo el recambio de agua de lastre en el océano abierto (Murphy et al. 2004, Dobbs \& Rogerson 2005). En ese contexto este plan de gestión considera como primer paso la revisión del reporte de agua de lastre. La tasa de invasión es mayor cuando los buques declaran no haber realizado el recambio de agua de lastre (Holeck et al. 2004), en cambio, cuando este se ejecuta, se logra reducir la concentración de zooplancton en un orden de magnitud, cambiando la dosis media de propágulos de $10^{7} \mathrm{a}$ $10^{6}$ (Minton et al. 2005). Por tanto, es una práctica probada en la mitigación de la transferencia y potencial introducción de especies (Albert et al. 2013) y hasta el momento la opción preferida por quienes toman decisiones al respecto (Yang \& Perakis 2004), puesto que no requiere el uso de nuevas tecnologías (Minton et al. 2005). Además algunos métodos de tratamientos de agua para eliminar potenciales propágulos, pueden causar daños a las paredes del tanque de lastre (Dobbs \& Rogerson 2005), disminuyendo la vida útil de las embarcaciones. Por lo tanto, un enfoque simple debería centrarse en el recambio de agua de lastre (Minton et al. 2005, Brickman \& Smith 2007).

Las estrategias de manejo de agua de lastre se centran más en el vector que en las especies individuales (Minton et al. 2005). Así este plan de gestión preventivo considera como primera evaluación de riesgo, verificar la zona de procedencia del agua que será deslastrada en el puerto, por lo que requiere que se identifiquen previamente el o los puertos donadores de agua de lastre. Esta es una operación simple cuando se trata de buques graneleros, que cargan o descargan todo el cargamento en un puerto único, ya que es probable que el agua de lastre proceda de un puerto donador único. En contraste, los buques que transportan carga general, tienden a detenerse en numerosos puertos, cargando y descargando parcialmente su carga, y por ende también el agua de lastre. Como resultado de ello la composición de especies en el agua de lastre es probablemente mucho más compleja, haciendo el proceso de evaluación de riesgos más complicado (FMAM-PNUD-OMI 2009). No obstante, esta complejidad no impediría que se ejecute el plan de gestión, solo es necesario tener clara la procedencia del agua de lastre de cada tanque que será deslastrado y aplicar el procedimiento a cada tanque de lastre por separado. Así, en los 43 puertos (principales y secundarios) localizados en la Ecorregión Marina de Chile Central (BEAM 2015) ${ }^{6}$ esta propuesta sería replicable, sin embargo, requiere adaptar la información referente a la similitud ambiental entre el puerto receptor y el puerto donador de agua de lastre. Aunque para mayor certeza, se sugiere investigar las características particulares de cada puerto (David et al. 2013).

La segunda evaluación de riesgo de este plan de gestión preventivo utiliza un Coeficiente de Riesgo Global (CRG) como una herramienta predictiva para estimar cuantitativamente el riesgo potencial de la descarga de agua de lastre de un buque. El CRG fue seleccionado debido a la factibilidad de obtener la información de cada uno de los factores necesarios para su estimación. Existen otros modelos, como el propuesto por Reuser et al. (2013) que se basa en la probabilidad de invasión per cápita (PCIP), es decir, la probabilidad de que un organismo individual logre establecerse luego del deslastre. Para esto se requiere conocer la tasa de invasión histórica anual asociada al agua de lastre para una zona costera (nuevas especies invasoras por año) y el número total de organismos descargados en todos los puertos de una zona costera (organismos por año). Este modelo predictivo aún no es aplicable para la costa chilena, debido a la falta de información sobre las especies invasoras. Los autores se basan en la información proporcionada por la base de datos online del SERC, que hasta el momento solo cuenta con datos de las costas de Estados Unidos.

Para ejecutar la tercera evaluación de riesgo propuesta en este plan de gestión, se debe necesariamente realizar un muestreo, que permita verificar el recambio de agua de lastre. Se han realizado diversos estudios de la composición de especies planctónicas (Hallegraeff 1998, David et al. 2007, McCollin et al. 2008), virus y bacterias (Joachimsthal et al. 2002, 2004; Soto et al. 2005, Doblin \& Dobbs 2006, David et al. 2007) en el agua de lastre, lo que permitiría pensar en utilizar alguno de estos organismos como indicador del recambio. Al respecto, Soto et al. (2005) señalan que el tipo de bacterias que se pueden encontrar en el agua de lastre varía con el tiempo de confinamiento, por lo que estas servirían para determinar si se realizó o no el recambio del agua de lastre. Sin embargo, los métodos convencionales de pruebas microbiológicas son inapropiados para la evaluación del agua de lastre, ya que exigen un análisis que es demoroso (Joachimsthal et al. 2004), siendo que no se dispone de mucho tiempo entre la llegada, el deslastre y la partida de cada buque. Además, el muestreo de organismos en aguas de lastre es muy complejo debido a las diferencias en las dimensiones y comportamiento de estos organismos (David \& Perkoviè 2004, Frazier et al. 2013) (bacterias, fitoplancton, zooplancton, ictioplancton) que van desde nanómetros a centímetros y que exhiben una migración activa y una serie de comportamientos de flotabilidad: neutral, no neutral y ajustable (Brickman \& Smith 2007). Otra dificultad está dada por las diferencias en la construcción de los barcos y la disponibilidad de los puntos de muestreo. Todo esto complica la selección de los métodos de muestreo, no existiendo una metodología uniforme a nivel mundial (David \& Perkoviè 2004). Por estos motivos, se han propuesto parámetros para verificar el recambio de agua de lastre, que requieren un menor tiempo de análisis y una menor complejidad de muestreo. Sin embargo, todos ellos presentan diversos inconvenientes: Murphy et al. (2004) utilizaron elementos traza (Ba, Mo, V, U, Mn y P), Salinidad, Radio/Torio $\left({ }^{223} \mathrm{Ra} 2^{26} \mathrm{Ra} 2^{28} \mathrm{Ra}\right.$ $\mathrm{y}^{228} \mathrm{Th}$ ) y CDOM (materia orgánica cromofórica disuelta). Los autores determinaron que si bien la proporción Radio/ Torio es un buen indicador, se requiere un gran volumen de 
muestra (300 L), lo que hace que el proceso de muestreo sea lento, tardando aproximadamente dos horas por muestra. Esto hace poco factible su utilización. Respecto a la salinidad, Murphy et al. (2006) señalan que no es un buen parámetro por sí sólo, ya que no todos los puertos presentan grandes diferencias de salinidad con aguas oceánicas. En cuanto al uso de elementos traza, Murphy et al. (2008) determinaron que metales como $\mathrm{Fe}, \mathrm{Cu}$ y $\mathrm{Zn}$ no son útiles debido a la contaminación por el material del barco. En tanto, la factibilidad de la medición in situ (utilizando un fluorómetro portátil), la inmediatez del resultado de la medición y las diferencias en las concentraciones de CDOM entre zonas costeras y oceánicas (Murphy et al. 2013), hacen que este parámetro sea el seleccionado en este plan de gestión preventivo. No obstante, la medición de CDOM representa un desafío, puesto que permite diferenciar entre aguas distantes a $0,2 \mathrm{mn}$ y agua distantes a $100 \mathrm{mn}$. Como en Chile el recambio de agua de lastre se puede realizar a $12 \mathrm{mn}$ (DGTM. Y MM. ORDINARIO N $\left.{ }^{\circ} 12.600 / 98\right)^{1}$, la diferencia en la concentración de CDOM podría ser menor. Por ello se requiere, antes de establecer este plan de gestión, calibrar la medición, mediante muestreos, ajustando las diferencias de concentración entre agua costera y agua oceánica a la distancia de recambio que normalmente se usa en Chile.

La principal fortaleza de este plan de gestión está en su aplicabilidad. Los procedimientos de muestreo de agua de lastre pueden ser uniformes o selectivos (Mallman \& Asmus 2006). En los muestreos uniformes todos los barcos son sometidos a los mismos procedimientos estandarizados, lo que los hace costosos y técnicamente poco prácticos (Ta-Kang et al. 2014). En cambio en los procedimientos selectivos, como el propuesto en el presente trabajo, se considera el riesgo que cada buque representa para el puerto, por lo que pese a que requieren un gran volumen de información, es información de fácil obtención y análisis.

Los países miembros de la OMI son 171, incluido Chile, más 3 países como miembros asociados. Países como Venezuela, Panamá, Colombia, Brasil, Argentina, Australia, Nueva Zelanda, Canadá y Estados Unidos han implementado planes de gestión para las aguas de lastre y/o han delineado directrices al respecto.

En Chile, no existe una mención expresa respecto a un plan de gestión de agua de lastre entre los órganos del Estado que deben resguardar el medio marino (Bermúdez $2011^{8}$ ). Chile como nación en vías de desarrollo debe abordar la problemática del agua de lastre desde un enfoque precautorio, adoptando medidas como las del plan de gestión propuesto que facilitan una fiscalización eficiente del recambio de agua de lastre. Esta es una propuesta viable técnica y económicamente, que permitiría reducir los riesgos para el patrimonio natural de Chile.

\section{CONCLUSIONES}

Esta propuesta de gestión es factible de aplicar técnica y económicamente. Solo se necesita capacitar a personal técnico para que ejecute paso a paso el procedimiento. No requiere de muestreos caros y de largos tiempos de análisis.

Hacen falta investigaciones que permitan incrementar el conocimiento respecto a la distribución de especies con potencial invasor en el mundo y las zonas marinas de Chile con mayor grado de vulnerabilidad a estas especies.

Para mejorar el grado de certeza de la etapa de verificación de esta propuesta de gestión se deberían realizar mediciones en terreno que permitan establecer los rangos CDOM en aguas costeras y oceánicas del territorio marítimo chileno.

\section{Agradecimientos}

Agradezco al Profesor Wolfgang Stotz, que me incentivó a escribir esta revisión. Se agradece también a quienes contribuyeron con sus correcciones y comentarios a materializar esta publicación.

\section{LiterATURA CITADA}

Albert R, J Lishman \& J Saxena. 2013. Ballast water regulations and the move toward concentration-based numeric discharge limits. Ecological Applications 23(2): 289-300.

Avaria S, M Cáceres, P Muñoz, S Palma \& P Vera. 1999. Plan nacional sobre floraciones de algas nocivas en Chile, $31 \mathrm{pp}$. Comité Oceanográfico Nacional, Valparaíso. <http://www. cona.cl/descargas/planfan.pdf $>$

Bellefontaine N, F Haag, O Lindén \& O Matheickal. 2010. Emerging ballast water management systems. Proceedings of the IMO-WNU Research and Development Forum, Malmö, Sweden, WNU Publications, 305 pp.

Brickman D. 2006. Risk assessment model for dispersion of ballast water organisms in shelf seas areas. Canadian Journal of Fisheries and Aquatic Sciences 63: 2748-2759.

Brickman D \& P Smith. 2007. Variability in invasion risk for ballast water exchange on the Scotian Shelf of eastern Canada. Marine Pollution Bulletin 54: 863-874.

BWRA. 2003. Ballast water risk assessment (Activity 3.1). BWRA User Guide (v1.4) for the BWRA Database / GIS System. GEF/UNDP/IMO, Global Ballast Water Management Programme, 89 pp. International Maritime Organization (IMO), London.

Carlton JT. 1985. Transoceanics and interoceanics dispersal of coastal marine organisms: the biology of ballast water. Oceanography and Marine Biology Annual Review 23: 313-374.

Carlton JT. 1996. Patterns, process and predictions in marine invasion ecology. Biological Conservation 78: 97-106.

Carlton JT. 1999. The scale and ecological consequences of biological invasions in the world's oceans. In: Sandlund OT, PJ Schei \& A Viken (eds). Invasive species and biodiversity management, pp. 195-112. Kluwer Academic Publishers, Dordrecht. 
Carlton JT. 2001. Introduced species in US Coastal Waters: Environmental Impacts and Management Priorities, $36 \mathrm{pp}$. Pew Oceans Commission, Arlington.

Carlton JT \& JB Geller. 1993. Ecological roulette: The global transport of nonindigenuos marine organisms. Science 261(5117): 78-82.

Clarke C, T Hayes, R Hilliard, N Kayvanrad, H Taymourtash, A Parhizi, V Yavari \& S Raaymakers. 2003. Ballast water risk assessment, Port of Khark Island, Islamic Republic of Iran. GloBallast Monograph Series 8: 1-115. OMI, London.

Colautti R, I Grigorovich \& H MacIsaac. 2006. Propagule pressure: a null model for biological invasions. Biological Invasions 8: 1023-1037.

CONAMA. 2008. Biodiversidad de Chile: Patrimonios y desafíos, 640 pp. Ocho Libros Editores, Santiago.

Costello C, J Drake \& D Lodge. 2007. Evaluating an invasive species policy: ballast water exchange in the Great Lakes. Ecological Applications 17: 655-662.

Costello M, M Coll, R Danovaro, P Halpin, H Ojaveer \& P Miloslavich. 2010. A census of marine biodiversity knowledge, Resources, and Future Challenges. PLoS ONE 5(8): e12110. <doi:10.1371/journal.pone.0012110>

David M \& M Perkoviè. 2004. Ballast water sampling as a critical component of biological invasions risk management. Marine Pollution Bulletin 49: 313-318.

David M, S Gollasch, M Cabrini, M Perkovic, D Bosnjak \& D Virgilio. 2007. Results from the first ballast water sampling study in the Mediterranean Sea - the Port of Koper study. Marine Pollution Bulletin 54: 53-65.

David M, S Gollasch \& M Pavliha. 2013. Global ballast water management and the 'same location' concept: a clear term or a clear issue? Ecological Applications 23(2): 331-338.

Dinerstein E, D Olson, D Graham, A Webster, S Primm, M Bookbinder \& G Ledec. 1995. A conservation assessment of the terrestrial ecoregions of Latin America and the Caribbean, 174 pp. Documents \& Reports, The World Bank, Washington.

Dobbs F \& A Rogerson. 2005. Ridding ships' ballast water of microorganisms. Is it even possible to remove, kill, or 'inactivate' all of them -and if so, should we try? Environmental Science \& Technology 39(12): 259-264.

Doblin MA \& FC Dobbs. 2006. Setting a size-exclusion limit to remove toxic dinoflagellate cysts from ships' ballast water. Marine Pollution Bulletin 52: 259-263.

Drake JM \& DM Lodge. 2004. Global hot spots of biological invasions: evaluating options for ballast-water management. Proceedings of the Royal Society 271: 575-580.

Endresen Ø, H Behrens, S Brynestad, A Andersen \& R Skjong. 2004. Challenges in global ballast water management. Marine Pollution Bulletin 48: 615-623.

FMAM-PNUD-OMI Asociaciones GloBallast y el IIO. 2009. Directrices para la evaluación de la condición jurídica y social nacional del agua de lastre. Monografía GloBallast, Series 17: 1-28. Unidad de Coordinación del Programa de las Asociaciones GloBallast / Organización Marítima Internacional, Londres.

Frazier M, A Whitman, H Lee \& D Reusser. 2013. Counting at low concentrations: the statistical challenges of verifying ballast water discharge standards. Ecological Applications 23(2): 339-351.
García M \& C Fernández. 2002. La introducción por mar de especies exóticas invasoras a través del agua de lastre de los barcos. El caso de Doñana, 111 pp. Universidad de Córdoba, Córdoba.

Gollasch S \& E Leppäkoski. 2007. Risk assessment of ballast water mediated species introductions - a Baltic Sea approach. Aquatic Invasion 2: 313-340.

Hallegraeff G. 1998. Transport of toxic dinoflagellates via ships' ballast water: bioeconomic risk assessment and efficacy of possible ballast water management strategies. Marine Ecology Progress Series 168: 297-309.

Hay C, S Handley, T Dodgshun, M Taylor \& W Gibbs. 1997. Cawthron's Ballast Water Research Programme Final Report 1996-1997, Cawthron Institute, Nelson. Report 417: 1-136.

Hayes K \& C Sliwa. 2003. Identifying potential marine pests - a deductive approach applied to Australia. Marine Pollution Bulletin 46: 91-98.

Hedgpeth JW. 1993. Foreign invaders. Science 261(6): 34-35.

Hewitt C \& M Campbell. 2007. Mechanisms for the prevention of marine bioinvasions for better biosecurity. Marine Pollution Bulletin 55: 395-401.

Holeck K, E Mills, H MacIsaac, M Dochoda, R Colautti \& A Ricciardi. 2004. Bridging troubled waters: Biological invasions, transoceanic shipping, and the Laurentian Great Lakes. BioScience 54(10): 919-929.

Hua J \& S Liu. 2008. Ballasting outside port to prevent spread of butyltin from merchant ships. Ocean Engineering 35: 1505-1511.

Hülsmann N \& B Galil. 2001. The effects of freshwater flushing on marine heterotrophic protists - Implications for ballast water management. Marine Pollution Bulletin 42: 1082-1086.

Joachimsthal E, V Ivanov, J-H Tay \& S Tay. 2002. Flow cytometry and conventional enumeration of microorganisms in ships' ballast water and marine samples. Marine Pollution Bulletin 46: 308-313.

Joachimsthal E, V Ivanov, S Tay \& J-H Tay. 2004. Bacteriological examination of ballast water in Singapore Harbour by flow cytometry with FISH. Marine Pollution Bulletin 49: 334-343.

Johnston E, R Piola \& G Clark. 2009. The role of propagule pressure in invasion success. Biological invasions in marine ecosystems. Ecological Studies 204: 133-151.

Keller R, J Drake, M Drew \& D Lodge. 2013. Linking environmental conditions and ship movements to estimate invasive species transport across the global shipping network. Diversity and Distributions 17: 93-102.

Lee H, D Reusser \& M Frazier. 2013. Approaches to setting organism-based ballast water discharge standards. Ecological Applications 23(2): 301-310.

Leung B, J Drake \& D Lodge. 2004. Predicting invasions: Propagule pressure and the gravity of Allee effects. Ecology 85(6): 1651-1660.

Locke A, D Reid, W Sprules, J Carlton \& H van Leeuwen. 1991. Effectiveness of mid-ocean exchange in controlling freshwater and coastal zooplankton in ballast water. Canadian Technical Report of Fisheries and Aquatic Sciences 1822: 1-93.

Lockwood J, P Cassey \& T Blackburn. 2005. The role of propagule pressure in explaining species invasions. TRENDS in Ecology and Evolution 20(5): 223-228. 
Mallman D \& M Asmus. 2006. Implementación de un modelo de evaluación de riesgo del agua de lastre en el puerto de Río Grande, Brasil. Investigaciones Marinas, Valparaíso 34(2): 205-210.

Matheickal J, S Raaymakers \& R Tandon. 2004. Ballast water treatment R\&D directory, 119 pp. International Maritime Organization, London.

Mendoza-Alfaro R \& P Koleff-Osorio. 2014. Introducción de especies exóticas acuáticas en México y en el mundo. En: Mendoza-Alfaro R \& P Koleff-Osorio (coord). Especies acuáticas invasoras en México, pp. 17-41. Comisión Nacional para el Conocimiento y Uso de la Biodiversidad, México, México

McCollin T, A Shanks \& J Dunn. 2008. Changes in zooplankton abundance and diversity after ballastwater exchange in regional seas Marine Pollution Bulletin 56: 834-844.

Minchin D \& S Gollasch. 2003. Fouling and ships hulls: how changing circumstances and spawning events may result in the spread of exotic species. Biofouling 19: 111-122.

Minton M, E Verling, M Whitman \& G Ruiz. 2005. Reducing propagule supply and coastal invasions via ships: effects of emerging strategies. Frontiers in Ecology and the Environment 3: 304-308.

Molnar J, R Gamboa, C Revenga \& M Spalding. 2008. Assessing the global threat of invasive species to marine biodiversity. Frontiers in Ecology and the Environment 6: 485-492.

Murphy K, G Ruiz, P Coble, J Boehme, P Field, J Cullen \& W Moore. 2002. Mid-ocean ballast water exchange: approach and methods for verification. Final Report to the US Coast Guard, Research and Development Center, 124 pp. Smithsonian Environmental Research Center, Edgewater.

Murphy K, J Boehme, P Coble, J Cullen, P Field, W Moore, E Perry, R Sherrell \& G Ruiz. 2004. Verification of midocean ballast water exchange using naturally occurring coastal tracers. Marine Pollution Bulletin 48: 711-730.

Murphy K, G Ruiz, W Dunsmuir \& T Waite. 2006. Optimized parameters for fluorescence-based verification of ballast water exchange by ships. Environmental Science \& Technology 40: 2357-2362.

Murphy K, P Field, T Waite \& G Ruiz. 2008. Trace elements in ships' ballast water as tracers of mid-ocean exchange. Science of Total Environment 393: 11-26.

Murphy K, J Boehme, C Brown, M Noble, G Smith, D Sparks \& G Ruiz. 2013. Exploring the limits of dissolved organic matter fluorescence for determining seawater sources and ballast water exchange on the US Pacific coast. Journal of Marine Systems 111/112: 157-166.

Oemcke D. 1998. The treatment of ship's ballast water. EcoPorts Monograph Series 18: 1-98. Ports Corporation of Queensland, Brisbane.

Ojaveer H, B Galil, D Minchin, S Olenin, A Amorim, J Canning-Clode, P Chainho, G Copp, S Gollasch, A Jelmert, M Lehtiniemi, C McKenzie, J Mikušm, L Miossec, A Occhipinti-Ambrogi, M Pexareviæm, J Pederson, G Quilez-Badia, J Wijsman \& A Zenetos. 2014. Ten recommendations for advancing the assessment and management of non-indigenous species in marine ecosystems. Marine Policy 44: 160-165.
OMI. 2004. Convenio internacional para el control y la gestión del agua de lastre y los sedimentos de los buques, $38 \mathrm{pp}$. Organización Marítima Internacional, Londres

Ramírez F. 2008. La bioseguridad marina en el régimen internacional de agua de lastre: amenazas, riesgos e intereses. X Coloquio Internacional de Geocrítica: Díez años de cambios en el mundo, en la geografía y en las ciencias sociales 1999-2008, 7 pp. Universidad de Barcelona, Barcelona

Reuser D, H Lee, M Frazier, G Ruiz, P Fofonoff, M Minton \& A Miller. 2013. Per capita invasion probabilities: an empirical model to predict rates of invasion via ballast water. Ecological Applications 23(2): 321-330.

Ricciardi A, L Jones, A Kestrup \& J Ward. 2010. Expanding the propagule pressure concept to understand the impact of biological invasions. In: Richardson DM (ed). Fifty years of invasion ecology: The legacy of Charles Elton 7: 225-235. Wiley-Blackwell, Oxford.

Ruesink J. 2005. Global analysis of factors affecting the outcome of freshwater fish introductions. Conservation Biology 19: 1883-1893.

Ruiz G, P Fofonoff, G Ashton, M Minton \& A Whitman. 2013. Geographic variation in marine invasions among large estuaries: effects of ships and time. Ecological Applications 23(2): 311-320.

Ruiz GM, PW Fofonoff, JT Carlton, MJ Wonham \& AH Hines. 2000. Invasion of coastal marine communities in North America: Apparent Patterns, Processes, and Biases. Annual Review of Ecology, Evolution, and Systematics 31: 481-531.

Ryan JA, JM Lishman \& JR Saxena. 2013. Ballast water regulations and the move toward concentration-based numeric discharge limits. Ecological Applications 23(2): 289-300.

Sala O, F Stuart, J Armesto, E Berlow, J Bloombeld, R Dirzo, E Huber-Sanwald, L Huenneke, R Jackson, A Kinzig, R Leemans, D Lodge, H Mooney, M Oesterheld, N LeRoy, M Sykes, B Walker, M Walker \& D Wall. 2000. Global biodiversity scenarios for the year 2100. Science 287: 1770-1774.

Sar E, M Ferrario \& R Reguera. 2002. Floraciones algales nocivas en el Cono Sur Americano, 311 pp. Instituto Nacional de Oceanografía, Madrid.

Seguí JM \& MR Martínez. 2004. Geografía de los transportes, 444 pp. Universitat de les Illes Balears, Palma de Mallorca.

Soto K, R Durán \& J Kuznar. 2005. Rapid examination of microorganisms in ballast waters. Revista de Biología Marina y Oceanografía 40(1): 77-82.

Spalding M, E Helen, R Gerald, N Davidson, Z Ferdaña, M Finlayson, B Halpern, M Jorge, A Lombana, S Lourie, K Martin, E McManus, J Molnar, Ch Recchia \& J Robertson. 2007. Marine ecoregions of the world: A bioregionalization of coastal and shelf areas. BioScience 57(7): 573-583.

Subba Rao D, W Sprules, A Locke \& J Carlton. 1994. Exotic phytoplankton from ships ballast waters: risk of potential spread to mariculture sites on Canada East coast. Canadian Data Report of Fisheries and Aquatic Sciences 937: 1-51.

Ta-Kang L, Ch-H Chang \& M LiChou. 2014. Management strategies to prevent the introduction of non-indigenous aquatic species in response to the Ballast Water Convention in Taiwan. Marine Policy 44: 187-195. 
Tamelander J, L Riddering, F Haag \& J Matheickal. 2010. Guidelines for development of national ballast water management strategies. GloBallast Monographs 18: 1-52.

Tapia C, K Vargas, C Muñoz, C Zepeda, I Núñez \& F Inostrosa. 2013. Gestión de recursos financieros para investigación, en base a riesgo, para la sustentabilidad de las pesquerías y la acuicultura. Informe Final Gestión de Riesgo CESSO, 102 pp. <http://www.subpesca.cl/portal/618/ articles-84758_documento.pdf $>$

Taylor F, J Hoppenrath \& J Saldarriaga. 2007. Dinoflagellate diversity and distribution. Biodiversity and Conservation 17: 407-418.

UNCTAD. 2008. Review of maritime transport. UNCTAD Report, 181 pp. United Nations, New York and Geneva. $<$ http://unctad.org/en/Docs/rmt2008_en.pdf $>$

Ubilla R. 2011. Problemática sobre el intercambio de agua de lastre y nuevas tecnologías para el tratamiento de esta. Tesis de Ingeniero Naval, Mención Máquinas Marinas, Escuela de Ingeniería Naval, Facultad de Ciencias de la Ingeniería, Universidad Austral de Chile, Valdivia, 88 pp.

Valenzuela J. 2013. Propuesta de criterios a considerar en la planificación de la fiscalización de resoluciones de calificación ambiental de proyectos incidentes en áreas silvestres protegidas del estado. Memoria de Ingeniero en Recursos Naturales Renovables, Escuela de Ciencias Agronómicas, Universidad de Chile, Santiago, 91 pp.
Van Holle B \& D Simberloff. 2005. Ecological resistance to biological invasion overwhelmed by propagule pressure. Ecology 86(12): 3212-3218.

Verling E, G Ruiz, L Smith, B Galil, A Miller \& K Murphy. 2005. Supply-side invasion ecology: characterizing propagule pressure in coastal ecosystems. Proceeding of The Royal Society B 272: 1249-1257.

Whitman M, M Minton \& G Ruiz. 2011. Geographic limitations and regional differences in ships' ballast water management to reduce marine invasions in the contiguous United States. BioScience 61(11): 880-887.

Wonham M, J Byers, E Grosholdz \& B Leung. 2013. Modeling the relationship between propagule pressure and invasion risk to inform policy and management. Ecological Applications 23(7): 1691-1706.

Wonham MJ, JT Carlton, GM Ruiz \& LD Smith. 2000. Fish and ships: relating dispersal frequency to success in biological invasions. Marine Biology 136: 1111-1121.

Yang Z \& A Perakis. 2004. Multiattribute decision analysis of mandatory ballast water treatment measures in the US Great Lakes. Transportation Research Part D 9: 81-86.

Ziller S, S Zalba \& R Dudeque. 2007. Modelo para el desarrollo de una estrategia nacional para el manejo de especies exóticas invasoras, 56 pp. Programa de Especies Exóticas Invasoras para Sudamérica, The Nature Conservancy Programa Global de Especies Invasoras (GISP), Curitiba. 